\title{
Measuring the modal parameters of a cultural heritage tower by using strong-motion signals
}

\author{
Mariella Diaferio ${ }^{1}$, Dora Foti ${ }^{1}$, Nicola Ivan Giannoccaro ${ }^{2}$, Salvador Ivorra ${ }^{3}$ \\ ${ }^{1}$ Depertment of Sciences of Civil Engineering and Architetture, Politecnico di Bari, Bari, Italy \\ 2 Department of Innovation Engineering, Università del Salento, Lecce, Italy \\ ${ }^{3}$ Department of Civil Engineering, University of Alicante, Alicante,Spain
}

\begin{abstract}
This paper presents the dynamic experimental campaign carried out on a stocky masonry clock tower situated in the Swabian Castle of Trani (Italy). The main objective of this paper is, after estimating the main frequencies and vibration modes of the considered structure, defining the transmission of vibrations along the height of the tower by varying the forced frequency at the base. At this aim, short acceleration records have been acquired simultaneously in 20 points of the tower at different levels, due to a series of sinusoidal forced vibrations applied at the base by using a pneumatic shaker device specifically designed for the tests. The proposed procedure permits to extract for each monitored point the amplitude of the sinusoidal component related to the excitation frequency and the phase shift due to the structure damping. The results of the proposed procedure are compared with the results of a classical operational modal analysis in environmental conditions in order to demonstrate that the short forced tests permit to classify the typology of the structural mode shapes.
\end{abstract}

\section{Section: RESEARCH PAPER}

Keywords: Operational Modal Analysis (OMA); forced vibrations of historical buildings; strong motion modal parameters identification; vibrodyne excitation

Citation: Mariella Diaferio, Dora Foti, Nicola Ivan Giannoccaro, Salvador Ivorra, Measuring the modal parameters of a cultural heritage tower by using strong-motion signals, Acta IMEKO, vol. 7, no. 3, article 14, October 2018, identifier: IMEKO-ACTA-07 (2018)-03-14

Section Editor: Sabrina Grassini, Politecnico di Torino, Italy

Received April 27, 2018; In final form September 13, 2018; Published October 2018

Copyright: (C) 2018 IMEKO. This is an open-access article distributed under the terms of the Creative Commons Attribution 3.0 License, which permits unrestricted use, distribution, and reproduction in any medium, provided the original author and source are credited

Funding: This work was supported by Structural Monitoring of ARTistic and historical BUILding Testimonies - (S.M.ART. BUIL.T.) Project of the European Territorial Cooperation Programme Greece-Italy 2007-2013 and by PRIN-MIUR 2010 research project entitled "Dynamics, Stability and Control of Flexible Structures"

Corresponding author: Mariella Diaferio, mariella.diaferio@poliba.it

\section{INTRODUCTION}

Historical buildings represent a large part of the cultura heritage of Italy. Among them towers represent the part that is more vulnerable to dynamic forces - and not only - due to their slenderness. Therefore, in the last decades, attention has been drawn to these structures and to their protection and safeguard. The design of interventions to reduce their vulnerability requires a deep knowledge of these structures for which, unfortunately, there is a lack of information because of their historical nature. Moreover, to assess their dynamic behaviour, non-destructive tests should be performed because of their historical character.

The tests are carried out recording data from a series of accelerometers installed in specific points of the structure and then Operational Modal Analysis (OMA) techniques [1]-[12] are applied in order to dynamically characterize the structure.
In the case of slender structures, such as towers, this type of investigation can give good results [4]-[6], because their vibrations are easily and clearly recordable even for low force intensity such as environmental loads.

In the present study, however, the tower considered for the analysis has a squat profile; its vibrations, therefore, are difficult to be recorded by the usual adopted accelerometers and equipment, and other kind of forcing must be applied. In fact, in these cases, the signals to be recorded are so low that could be confused with the noise which inevitably is present during the acquisitions. In order to guarantee a good ratio between the signal and the noise, forced vibrations are better to be utilized to get reliable information on the dynamic characteristics of the structure. Sometimes the input could be obtained from the swinging of the bells when the bells are present and working. In 
other cases, the use of a shaker mechanical device, usually called vibrodyne, could be considered, if it does not compromise the structure of the ancient monument. Examples of squat structures or forced excitation can be found in [10-13].

A vibrodyne is able to impress a known signal to the structure; therefore, it is possible to produce different unidirectional harmonic loads with a sweeping frequency depending on the mass of the shaker. Usually, a vibrodyne consists of moving/rotating masses by an electric motor. A method for forced vibration testing of structures is proposed in [14]. The method can identify a linear shaker input motion, which produces a structural response like that of the building subjected at the base by a seismic force, and pre-correct the input motion to account for control-structure interaction effects.

A vibrodyne was also utilized to test the civic tower of Rieti (Italy), which was equipped with a Tuned Mass Damper (TMD) system placed on the roof of the building [15-16]. It is utilized to experimentally assess the behaviour of composite structures [17].

In order to get the dynamic response of the squat clock tower of the Castle of Trani (same characteristics of the structural analysis in [18]) an appropriately realized electrohydraulic shaker device (vibrodyne) has been used to generate forced oscillation on the tower.

In this paper the equipment and the experimental setup that has been used for in-situ dynamic identification tests on the squat clock tower of Trani's Castle (in Italy) are described and an extensive analysis about the effects of the shaking device on the vibrations of the tower is presented completing the preliminary analysis shown in [7]. The performed analysis may be considered very particular and innovative in this field for the opportune post processing elaboration which may underlined the relevant characteristics of structural transmission damping ratio at the different excitation frequencies. The comparison of the extracted transmitted amplitudes and phase shift in the monitored points with the identified mode shapes at different frequencies validates the proposed strategy that has the advantage of giving precise structural transmissivity information at different frequencies.

\section{GEOMETRICAL DESCRIPTION}

The clock tower here considered is part of the Swabian Castle of Trani (South-East of Italy). More in detail it is located on the eastern façade, on the main entrance of the castle [19]. The latter was built on the edge of town and the height of the towers allowed to guard the entrance of the port and the access roads to the village. The castle, originally had a simple and functional quadrangular enhanced layout with four square towers of the same height. The castle, with the succession of dynasties, the first Angioin, then the Aragonese, was always, to this day, owned by the government, except for a brief period (1385-1419), when it was assigned to Captain Alberico da Barbiano. In the sixteenth century, with the advent of the first weapons, the castle was adapted to the new defensive techniques, in response to widespread demand for refortification of the Mediterranean coast, under threat from the Turks. These operations involved the rise of the southern front, least favourite course and overlooking towards the open country, and the construction of two bastions at opposite edges to the southwest (a spear) and northeast (square), thus ensuring a complete fire coverage around the perimeter of the fortress.
The Castle has played its military role continuously, except for the years 1958-1677, when it hosted the "Holy Royal Audience" in the province of Bari, until, in the nineteenth century, it was transformed into rent provincial destination maintained until 1974.

The clock tower of the castle, in limestone, was added to the main entrance on the west side in the nineteenth century, just when Ferdinand II Duke of Bourbon converted it in the provincial Central Prison. In 1844, in fact, it came up the need to equip the prison with a clock to adjust the internal life of the prison and in 1848 the new clock tower was built in order to make the sound of the clock reaching the whole castle.

With this change of use of the entire castle underwent many changes, but fortunately the work of the nineteenth century were only superimposed to the old structures. The new clock tower, in fact, was built on the old walls of the fortress. In 1976 it was delivered to the Superintendence for Architectural, Artistic and Historical Heritage of Apulia. From 1979 to 1998 the entire castle was then restored and almost all the additions of the period of the prison were demolished.

At present it can be visited as a historical monument and the clock tower maintains its use like a clock.

The clock tower has an overall height equal to $7.20 \mathrm{~m}$ from its main door. The tower has a square plan transversal section, with the inner side of about $2.05 \mathrm{~m}$, constant along the total height, while the outer side is variable along the height because of the presence of a Trani stone covering. In fact, the outer side is $4.25 \mathrm{~m}$ at the base and $3.55 \mathrm{~m}$ at the intermediate height of $4.00 \mathrm{~m}$ and, from this level up to the top, it keeps constant. At the intermediate height of $4.60 \mathrm{~m}$ there is also a toroidal stringcourse. The tower façades are characterized by openings arranged on two different levels: (i) At the lower level, there is the doorway on the west side, while on the other sides, there are archivolted windows with a width of about $1.40 \mathrm{~m}$ and an average height of $60 \mathrm{~cm}$. (Figure 1b). (ii) At the upper level, there are archivolted windows smaller than the previous ones, with a width of $85 \mathrm{~cm}$ and a height of $55 \mathrm{~cm}$, arranged on all sides except for the east one, which is blind to host the large central clock. (Figure 1a). On the eastern facade, differently by the other ones, the masonry keeps for about $2.25 \mathrm{~m}$, with a gabled portal with an arched opening in the middle where a bell is located.

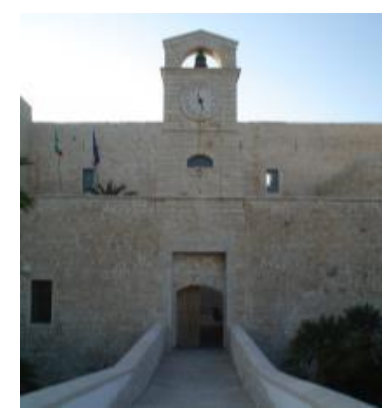

(a)

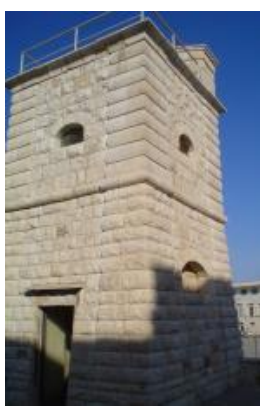

(b)

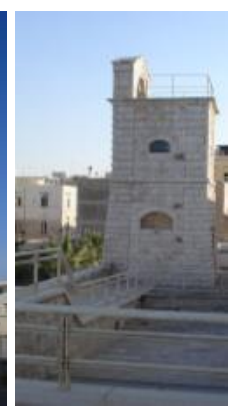

(c)
Figure 1. Clock tower. Trani's Swabian Castle: (a) East view; (b) West view; (c) South view.

\section{THE EXPERIMENTAL TEST}

To evaluate the tower main frequencies and its experimental mode shapes, the tower has been instrumented with 23 high sensitivity seismic accelerometers ICP PCB 393 B31 with a sensitivity of about $10 \mathrm{~V} / \mathrm{g}$. All the accelerometers were 
connected by flexible wired cables to a NI data acquisition system, the latter connected to a laptop with a specific acquisition software positioned at the base of the tower.

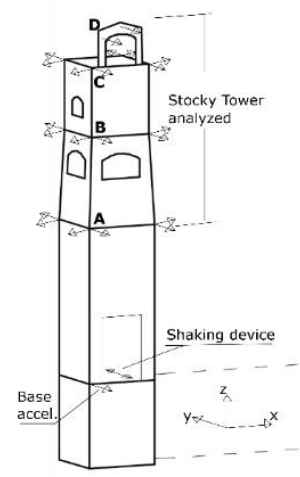

(a)

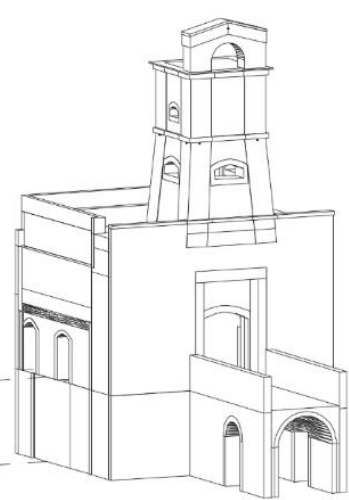

(b)
Figure 2. Experimental setup: (a) Positions and directions of acquisition of the 23 accelerometers; (b) Tower's 3D view.

The accelerometers were placed at four different levels on the four lateral sides of the tower: 8 accelerometers at the four corners of the floor over the clock, 6 accelerometers at three corners at the intermediate level, 6 at the three corners at the lower level as part of the clock tower, and 1 accelerometer at the basis as a reference sensor (Figure 2a). Appropriate rectangular blocks, where the accelerometers were inserted with screws, were used for ensuring the orthogonality of each couple of accelerometers installed in the same point. It is important to note the points $\mathrm{A}, \mathrm{B}, \mathrm{C}$ and $\mathrm{D}$, aligned on the left part of the tower and placed at different levels (Figure $2 \mathrm{a}$ ) and the points E, F and $G$ aligned with $A, B$ and $C$ on the opposite side of the front of the tower.

Two accelerometers were placed on the superior arch for monitoring the oscillation of the upper part, probably the most significant local modes for stability analysis.

\subsection{Environmental tests results}

Four consecutive acquisitions of environmental vibrations (called Test 1, Test 2, Test 3 and Test 4) were carried out by recordings of $15 \mathrm{~min}$ each with a sampling frequency of $1024 \mathrm{~Hz}$.

The specific ARTeMIS software [20] was used for the extraction of the modal parameters. Two different OMA methods were used for each analysis: the Enhanced Frequency Domain Decomposition (EFDD), which operates in the frequency domain, and the Stochastic Subspace Identification (SSI) using Unweighted Principal Components (UPC), which operates in the time domain. In this analysis, the SSI method has demonstrated to be able to better estimate the frequencies when it works at $1024 \mathrm{~Hz}$. Figure 3 shows the SSI diagram of the first environmental test and the frequencies of the tower clearly identified.

The identified frequencies (in $\mathrm{Hz}$ ) for the 4 tests conducted under environmental actions are summarized in Table 1. It is evident the good repeatability of the identified frequencies for all the environmental tests; moreover, similar results were obtained also adopting the EFDD technique. So, nevertheless the squat profile of the analyzed tower, the power of the recent OMA techniques and the sensitivity of the available sensors permit to identify with a good confidence the frequencies and the corresponding mode shapes. The same confidence is not possible for the evaluation of the damping ratios; for this reason, the structure has been forced with a specific electrohydraulic shaker (vibrodyne) designed for exciting the structure from the basis. The mode shapes corresponding to the identified frequencies are related to bending modes (along y and $x$ axis indicated in Figure 2, respectively) for the first two frequencies; the third frequency is related to a torsional mode, the fourth frequency to a second bending mode (y axis), the fifth frequency to a bending-torsional mode, the sixth one to a torsional mode.

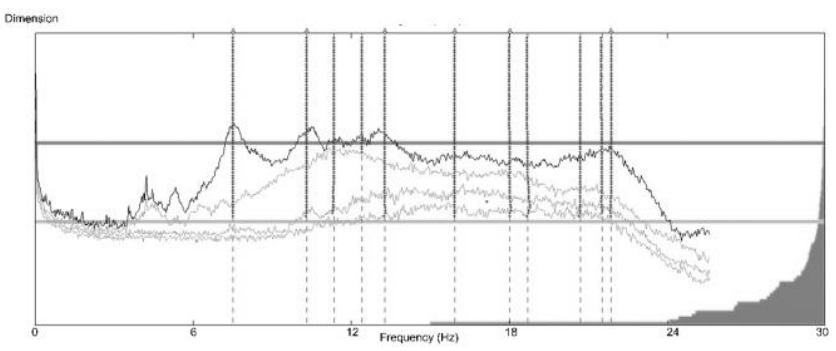

Figure 3. SSI diagram for the Test 1.

\subsection{Forced tests results}

As aforementioned, other tests have been performed by installing a vibrodyne at the main entrance of the Tower (Figure 4). The vibrodyne accumulator was charged by an electric motor. The vibrodyne was installed between two frames to anchor it to the base of the tower by means of four screws (Figure 4 b).

The forces produced by the vibrodyne were characterized by a chosen frequency and a fixed amplitude.

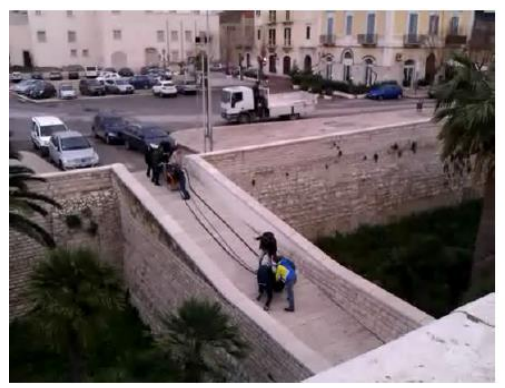

(a)

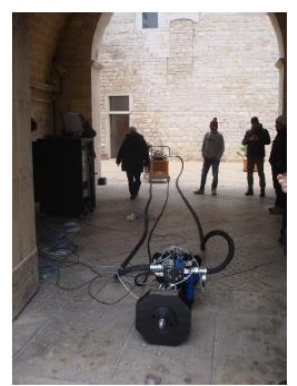

(b)
Figure 4. a) Transportation of the vibrodyne; b) Vibrodyne installed at the main entrance of the clock tower.

Table 1. Identified frequencies for the 4 environmental tests using the SSI technique.

\begin{tabular}{ccccc}
\hline $\begin{array}{c}\text { Frequency } \\
\text { order }\end{array}$ & $\begin{array}{c}\text { Test 1 } \\
\mathbf{H z}\end{array}$ & $\begin{array}{c}\text { Test 2 } \\
\mathbf{H z}\end{array}$ & $\begin{array}{c}\text { Test 3 } \\
\mathbf{H z}\end{array}$ & $\begin{array}{c}\text { Test 4 } \\
\mathbf{H z}\end{array}$ \\
\hline $1^{\text {st }}$ & 7.52 & 7.5 & 7.48 & 7.53 \\
$2^{\text {nd }}$ & 10.32 & 10.36 & 10.34 & 10.31 \\
$3^{\text {rd }}$ & 13.28 & 13.33 & 13.35 & 13.51 \\
$4^{\text {th }}$ & 15.93 & 15.98 & 15.79 & 16.09 \\
$5^{\text {th }}$ & 18.08 & 18.34 & - & - \\
$6^{\text {th }}$ & 21.85 & 21.83 & 21.83 & 22.08 \\
\hline
\end{tabular}


A preliminary test was carried out considering an excitation produced by a $200 \mathrm{~kg}$ moving mass having the same amplitude and changing the frequency from $1 \mathrm{~Hz}$ to $15 \mathrm{~Hz}$, with a step of $2 \mathrm{~Hz}$ modified about every 2 min. Figure 5 shows the temporal acceleration values during the tests in points $\mathrm{A}, \mathrm{B}, \mathrm{C}$ and $\mathrm{D}$ placed at different levels as indicated in Figure 2. The final $80 \mathrm{~s}$ of acquisition have been done switching off the diesel motor, only with the pressure accumulated in the accumulator, to evaluate the influence of the motor on the recorded oscillations; it is evident that there is a brusque diminution of the oscillations.

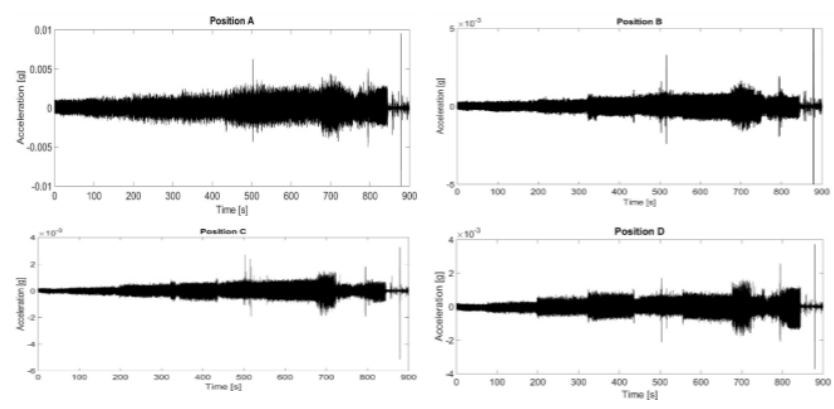

Figure 5. Accelerations in the positions A, B, C and D during the forced tests, the final $80 \mathrm{~s}$ are acquired after switching off the motor.

From figure 5, it is evident that the shaker device amplifies the oscillations in all the monitored points of the tower. Considering the last $80 \mathrm{~s}$ of Figure 5 when the pump motor is off, the results clearly show that the dominant effect of the oscillations is due to the pump motor. This preliminary analysis convinced to use the shaker device with only the accumulator power (motor switched off), in order to excite the structure avoiding the vibrations of the motor.

The preliminary analysis was very useful for arranging further tests without doubts about the possibility of acquiring data only related to the shaker device forcing action and not influenced by the pump motor effects.

Short tests were carried out using only the accumulator energy as forcing action. However, the accumulator autonomy was very short and also depending by the frequency; for a frequency of $3 \mathrm{~Hz}$ the accumulator had $110 \mathrm{~s}$ of autonomy, but it decreased to about $50 \mathrm{~s}$ for $9 \mathrm{~Hz}$, to about $25 \mathrm{~s}$ for $18 \mathrm{~Hz}$ and to only $15 \mathrm{~s}$ of autonomy for $20 \mathrm{~Hz}$.

\subsection{Filtering procedure}

In order to analyze directly the effect of each forced frequency at the base with each response at each position on the tower an innovative strategy is here introduced to use the forced vibration signals in a more specific way.

The approach is based on considering a digital filtering of the acquired signals; in detail, a classical windowed linear-phase FIR digital filter has been designed [21]. The filter is normalized so that the magnitude response of the filter at the center frequency of the passband $W n=\left[\begin{array}{ll}w 1 & w 2\end{array}\right]$ is $0 \mathrm{~dB}$. The FIR filter is a non-recursive one because the output signal is a function only of the input signal $u$. The response of such a filter to a generic input signal is a finite sequence of $m+1$ samples, where $\mathrm{m}$ is said the filter order. In order to generalize the response to any input signal, the system function $\mathrm{H}(\mathrm{z})$ of the FIR filter has to be evaluated. It is the Z-transform of the impulse response that is the output when the Kronecker delta function $\delta$ is given as input. The system function $\mathrm{H}(\mathrm{z})$ is calculated in (1) where $a_{0}$ and $b_{\mathrm{i}}(\mathrm{i}=0, \ldots, \mathrm{m})$ are constant coefficients, with $a_{0}, b_{\mathrm{m}} \neq 0$.

$H(z)=Z[h(k)]=\frac{1}{a_{0}} Z\left[\sum_{i=0}^{m} b_{i} \delta(k-i)\right]=\frac{1}{a_{0}} \sum_{i=0}^{m} b_{i} z^{-i}$

The aim of filtering the acquired signal was achieved by the calculation of the coefficients $b_{i}(i=0, \ldots, m)$ through the fir 1 function in Matlab [22]. A two element vector [ $\left.\mathrm{w}_{\mathrm{l}} \mathrm{w}_{\mathrm{h}}\right]$ was passed to this function of the Signal Processing Toolbox in such a way as to specify the band of normalized frequencies for bandpass configuration. This is a Hamming-window based, linear-phase filter with normalized cut-off frequency. The lower and upper bound filters were chosen as in equation (2). Different values for the parameter $\varepsilon$ were firstly settled for testing the filter capabilities and subsequently the value $0.05 \mathrm{~Hz}$ was fixed to obtain the desired bandwidth.

$w_{l}=2\left(\frac{f-\varepsilon}{f_{s}}\right), w_{h}=2\left(\frac{f+\varepsilon}{f_{s}}\right)$

\subsection{Application of the filtering process to the forced vibrations data}

The application of digital filters to experimental accelerometers data in environmental conditions have been recently tested by the authors [23], [24], [25] In [23] the postprocessing has permitted to synchronize different wireless accelerometers by analysing the phase of the signals; in [24] it was demonstrated that, for environmental data, a digital fir filter is not able to separate an accurate sinusoidal signal for the effect of close components. In this paper, the digital technique is applied to forced vibrations data, considering the band-pass central frequency coincident with the shaker device excitation frequency. The digital post-processing has been successfully applied to all the acquired accelerometers data. In the following the data referred to four acquisition points A, B, C, D along the y direction will be analysed.

The filtered signal and its frequency spectrum in comparison with the original signal and its spectrum are shown for the case of excitation at $9 \mathrm{~Hz}$ for points $\mathrm{A}, \mathrm{B}, \mathrm{C}, \mathrm{D}$, and, for point $\mathrm{A}$, also for the case of $16 \mathrm{~Hz}$ and $18 \mathrm{~Hz}$ excitation in Figures 6-9. It is evident that the digital filter is able to eliminate the external components to the forcing frequency and that the filtered signal is almost sinusoidal with a very low fluctuation regarding its amplitude, considering a transitory time of $1 \mathrm{~s}$.

The same effect has been carried out for all the acquired accelerometers data and for all the considered excitation frequency.
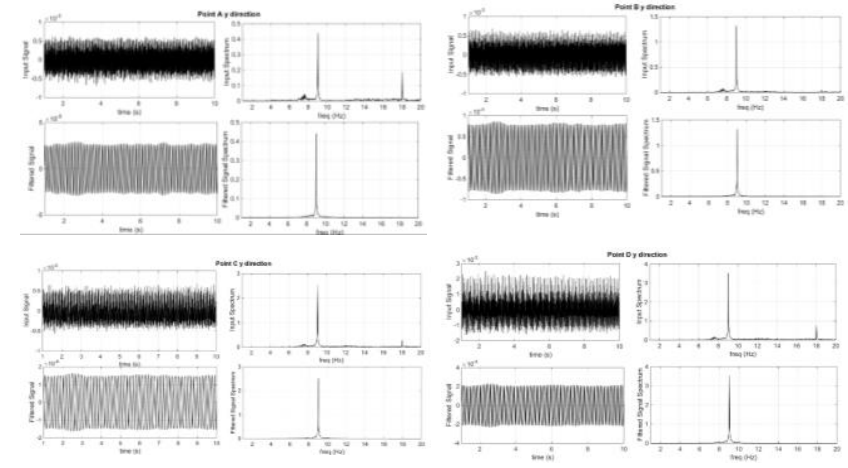

Figure 6. Filtering effect for points A, B, C and D, excitation frequency at $9 \mathrm{~Hz}$. 
For all the considered filtered sinusoidal signals it is possible to calculate automatically the amplitude as the average value of half of the peak to peak value all over the full acquisition period, and also an initial phase angle may be calculated for estimating the delay respect to the initial evaluation time of the first maximum.
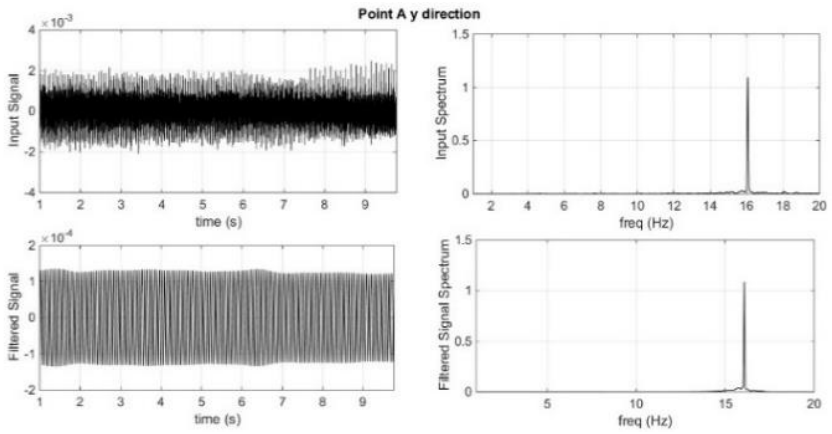

Figure 7. Filtering effect for point A, excitation frequency at $16 \mathrm{~Hz}$.

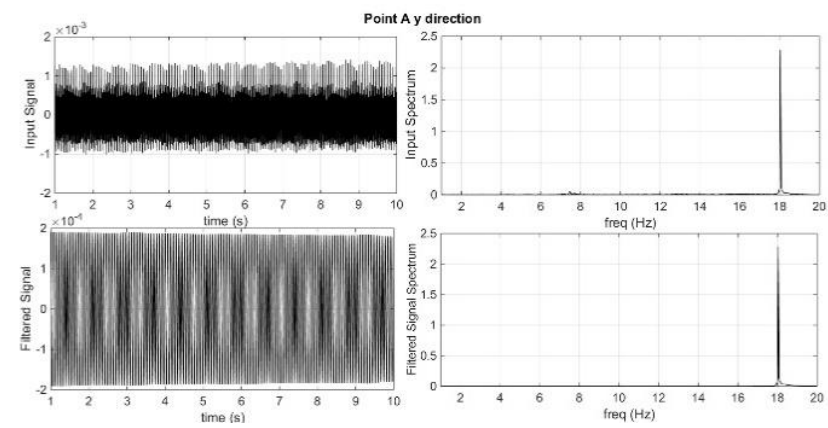

Figure 8. Filtering effect for point A excitation frequency at $18 \mathrm{~Hz}$.

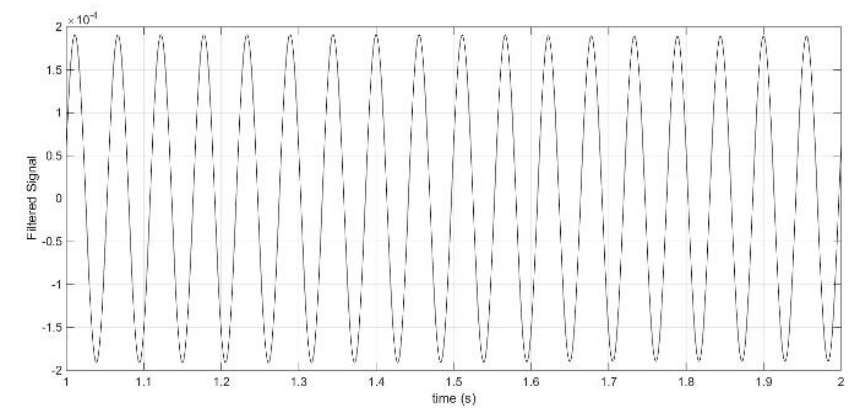

Figure 9. Zoom of the filtering effect for point A (y direction), excitation frequency at $18 \mathrm{~Hz}$.

In order to compare the effect of the digital filter with the environmental situation, in Figure 10 also the case of environmental excitation is shown with reference to the same point A (y direction) and considering the same digital filter centered at the first estimated frequency $(7.5 \mathrm{~Hz})$. This demonstrates the necessity of the shaker device effect that allows to analyse the data as really forced vibration data, using parameters such as the amplitude and the phase angle also for testing the dynamic behavior of the structure.

\section{ANALYSIS OF THE FILTERED FORCED VIBRATION DATA}

The parameters obtained by means of the described filtering procedure may be analysed for extracting further interesting information about the modal parameters which characterize the structure but also about the transmissibility of the forced oscillations at different levels and from different sites of the structure. In the present research, 7 significant points have been considered, already introduced in Paragraph 3, and constituting two vertical lines placed at the left part (points A, B, C and D) and at the right part (point E, F, G) at the same level of the tower. For each of the aforementioned seven points both the accelerometers (along direction indicated with $\mathrm{x}$ and $\mathrm{y}$, see Figure 2) have been considered in such a way to have an idea of the spatial behaviour of the structure.

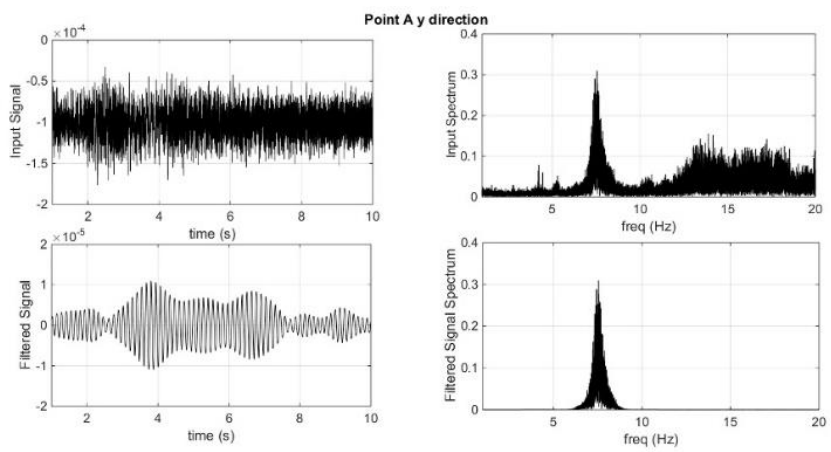

Figure 10. Filtering effect for point $A$, environmental conditions.

\subsection{Excitation frequency at $9 \mathrm{~Hz}$}

The peak to peak amplitude for the seven considered points along the y direction is represented in Figure 11 by considering the different height of the consider points with respect to the ground (where the vibrodyne is installed). The trend is crescent in an almost quadratic way and the interesting thing is that the values of the filtered peak to peak transmitted vibrations are very close in both the two sides of the front part of the tower. Moreover, the corresponding phase values, evaluated respect to the phase of the accelerometer in point A (y direction) and shown in Figure 12 clearly show that all the filtered signal are perfectly in phase with a very low phase shift on the two considered lines of points.

The trend carried out in Figures 11 and 12 is typically associated with a first flexural behavior; effectively, considering the environmental test results shown in paragraph 3 , there is a flexural mode directed along y axis around $7.5 \mathrm{~Hz}$. The sinusoidal force at $9 \mathrm{~Hz}$ has been able to excite the flexural mode and the proposed procedure permits to detect the flexural behavior with an acquisition of around one minute.

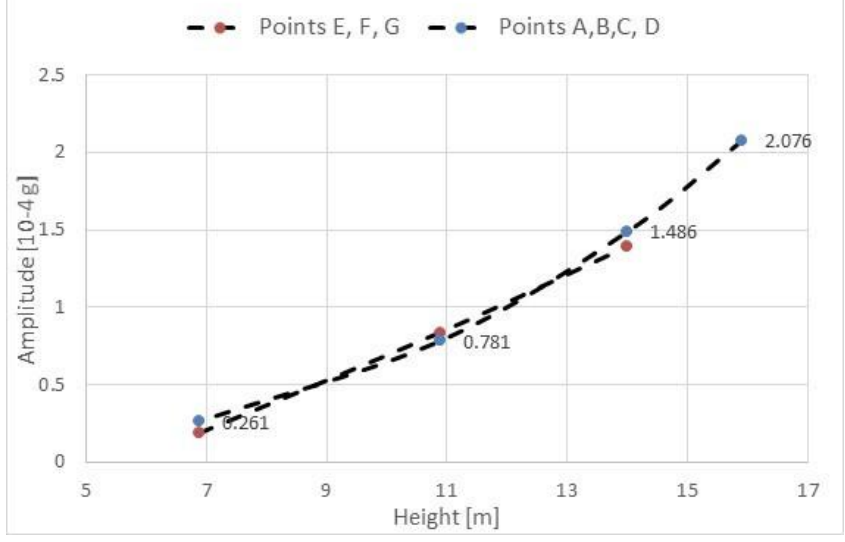

Figure 11. Excitation frequency of $9 \mathrm{~Hz}$ : peak amplitude of the analyzed points, y direction. 


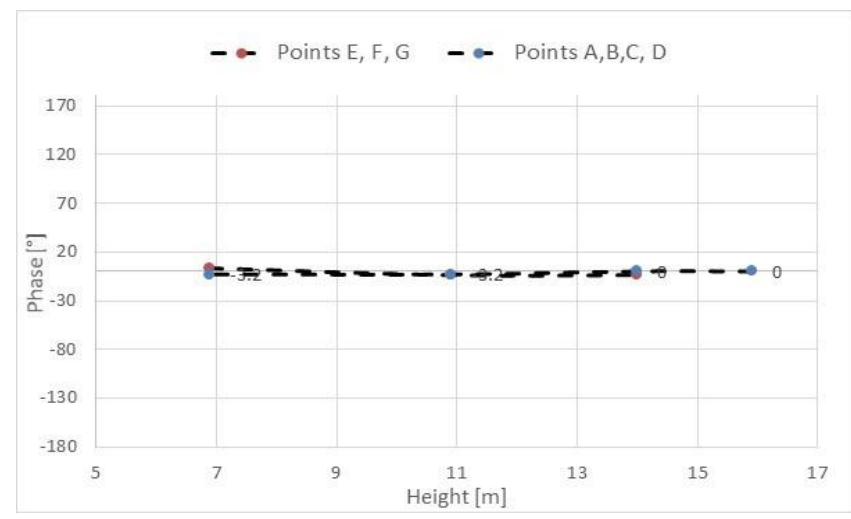

Figure 12. Excitation Frequency of $9 \mathrm{~Hz}$ : phase shift of the analyzed points, y direction

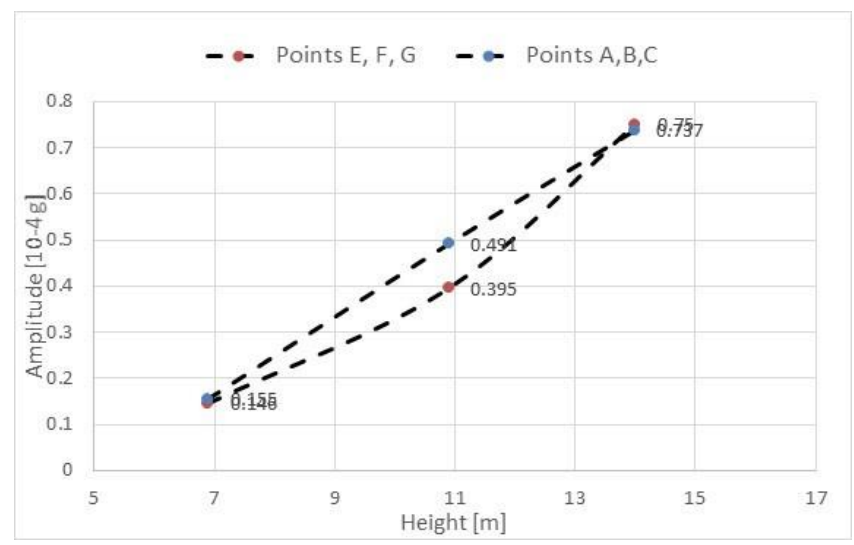

Figure 13. Excitation frequency of $9 \mathrm{~Hz}$ : peak amplitude of the analyzed points, $x$ direction

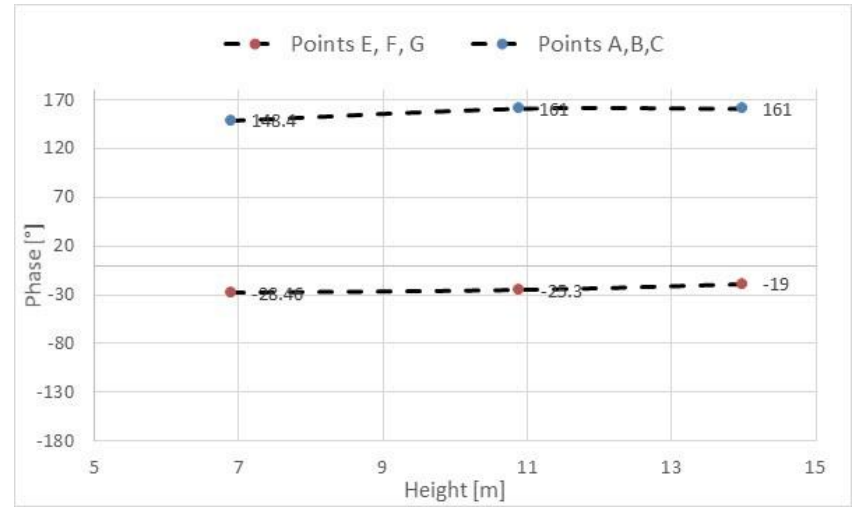

Figure 14. Excitation Frequency of $9 \mathrm{~Hz}$ : phase shift of the analyzed points, $x$ direction

\subsection{Excitation frequency at $16 \mathrm{~Hz}$}

Analysing by means of the proposed procedure the forced data with excitation frequency of $16 \mathrm{~Hz}$ (corresponding as shown in paragraph 3 at about the value of the second flexural mode along y axis), the peak amplitude and the phase shift along y axis shown in Figures 15 and 16 have been obtained. It is evident that the situation is changed with respect to the previous case; the peak amplitude has not an increasing behavior (with respect to the height) but it has a minimum point at about the center of the tower for both the lines constituted by the points A-B-C-D and E-F-G. This behavior is in accordance with the second flexural mode shape. Moreover, there is an increasing phase shift which arrives at about $170^{\circ}$ between the extreme point $A$ and $D$ and $160^{\circ}$ between $E$ and $G$ confirming the plausibility of a second flexural mode along y.

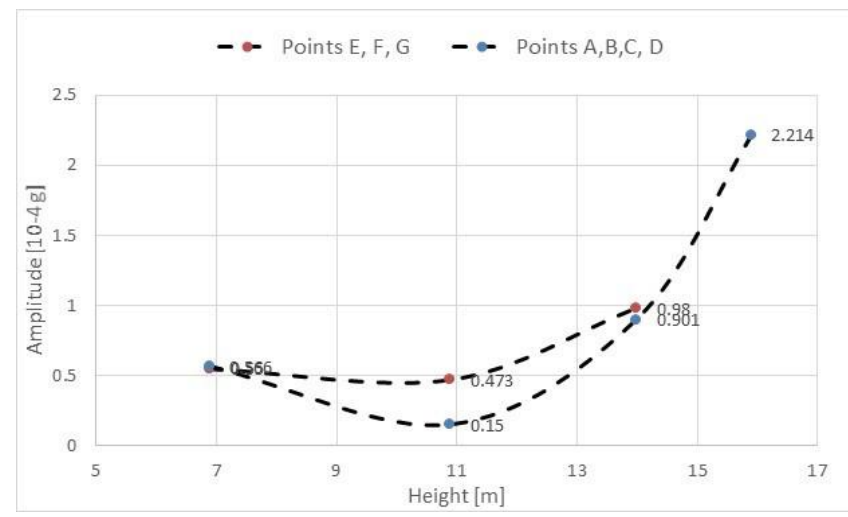

Figure 15. Excitation frequency of $16 \mathrm{~Hz}$ : peak amplitude of the analyzed points, y direction

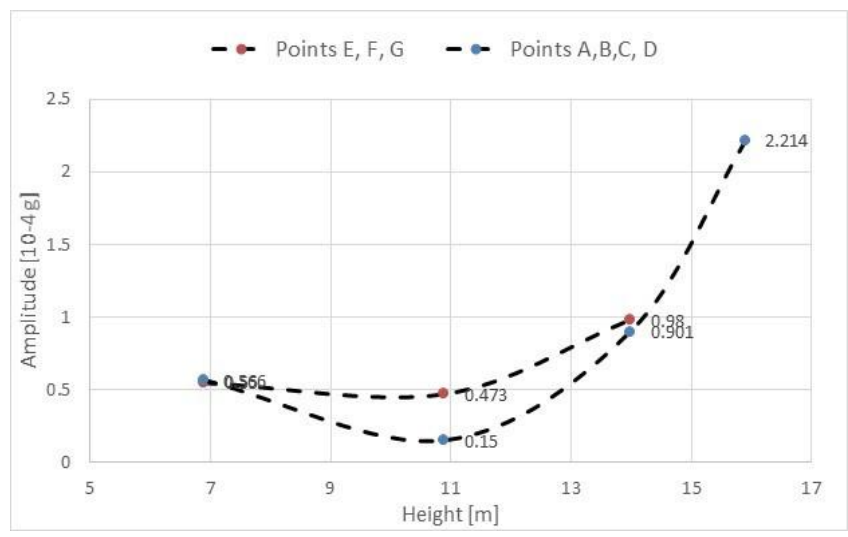

Figure 16. Excitation frequency of $16 \mathrm{~Hz}$ : phase shift of the analyzed points, y direction

A further confirmation may be obtained by evaluating the peak amplitude (Figure17) and phase shift (Figure18) along $\mathrm{x}$ axis, where, confirming a peak decreasing around half of the height, there is not anymore a phase shift of around $180^{\circ}$ between extreme points.

Moreover, considering that the second mode (flexural along $\mathrm{x})$, has been estimated around $10.5 \mathrm{~Hz}$, the same analysis has been conducted for the accelerometers placed along the $\mathrm{x}$ direction (points A-B-C and E-F-G) and the results are shown in Figures 13 and 14. It is evident that the peak amplitudes transmitted have the same shape of the $y$ direction (lower value) and that there is a constant phase between the points A-B-C and E-F-G.

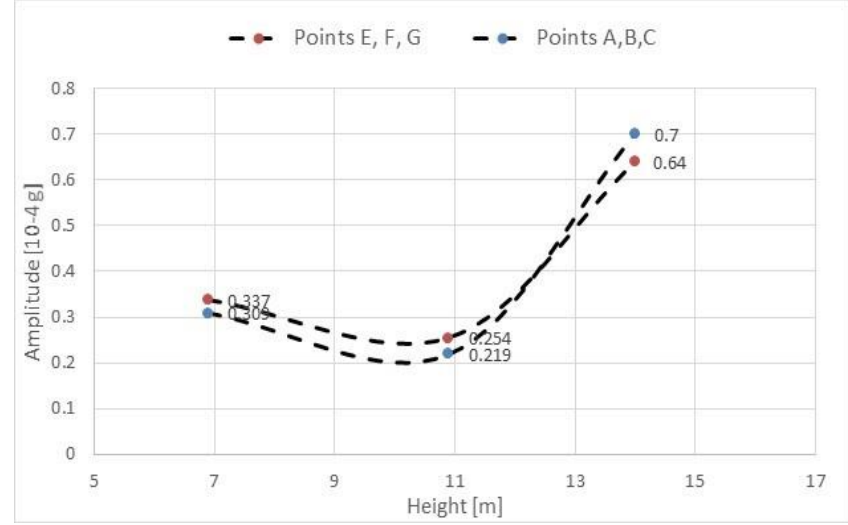

Figure 17. Excitation Frequency of $16 \mathrm{~Hz}$ : peak amplitude of the analyzed points, $x$ direction 


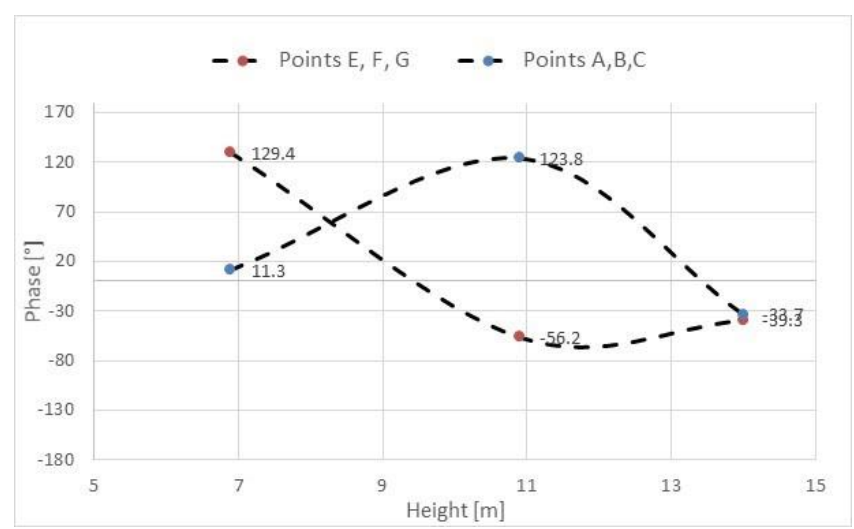

Figure 18. Excitation Frequency of $16 \mathrm{~Hz}$ : phase shift of the analyzed points, $x$ direction

\subsection{Excitation frequency at 18 and $20 \mathrm{~Hz}$}

The excitation at 18 and $20 \mathrm{~Hz}$ are referred, as identified in paragraph 3, mainly to bending-torsional and torsional modes of the structure. The results along y axis for peak amplitude and phase shift are shown in Figures 19-20 (excitation at $18 \mathrm{~Hz}$ ) and Figures 21-22 (excitation $20 \mathrm{~Hz}$ ).

The results of Figures 19-22 are completely different from the results with excitation frequency at $9 \mathrm{~Hz}$ and also are quite different from the ones for excitation frequency at $16 \mathrm{~Hz}$. It is immediate to recognize for the excitation frequency at $20 \mathrm{~Hz}$ a very different behavior (both in phase and in peak amplitude) between the two different sides of the tower which is justifiable with a heavy torsional effect excited at that frequency (as it appears from the results in paragraph 3).

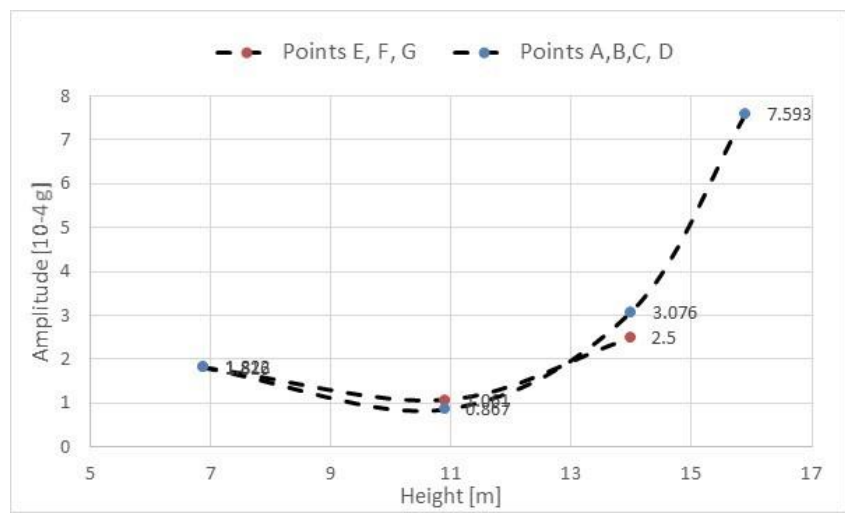

Figure 19. Excitation Frequency of $18 \mathrm{~Hz}$ : peak amplitude of the analyzed points, $y$ direction

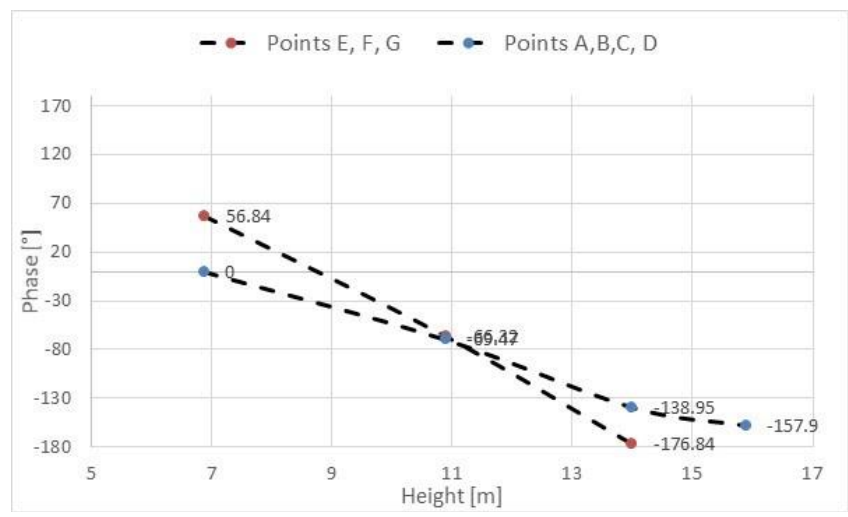

Figure 20. Excitation Frequency of $18 \mathrm{~Hz}$ : phase shift of the analyzed points, y direction

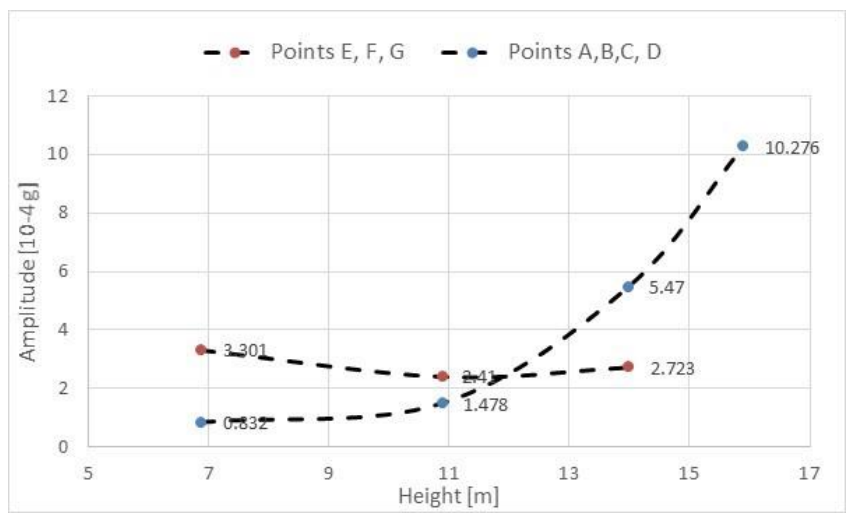

Figure 21. Excitation Frequency of $20 \mathrm{~Hz}$ : peak amplitude of the analyzed points, $y$ direction

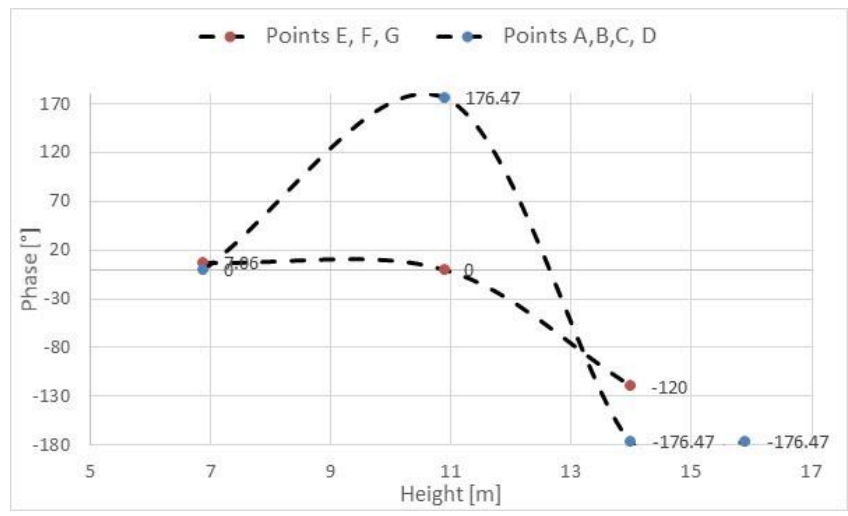

Figure 22. Excitation Frequency of $20 \mathrm{~Hz}$ : phase shift of the analyzed points, y direction

Moreover, at $18 \mathrm{~Hz}$, there is a slight different behavior about the phase between the two sides while the peak amplitudes are quite comparable between the two sides. This is also justifiable because the mode at $18 \mathrm{~Hz}$ has been classified as a flexuraltorsional mode, so it has some characteristics of a flexural mode but also a phase shift difference at the opposite sides.

In order to complete the presentation of the analysis, in Figures 23-26 are depicted the results along the $\mathrm{x}$ direction for the considered excitation frequencies of 18 and $20 \mathrm{~Hz}$.

The last figures confirm the torsional effect evident for the excitation at $20 \mathrm{~Hz}$ and the flexural-torsional effect of the excitation at $18 \mathrm{~Hz}$.

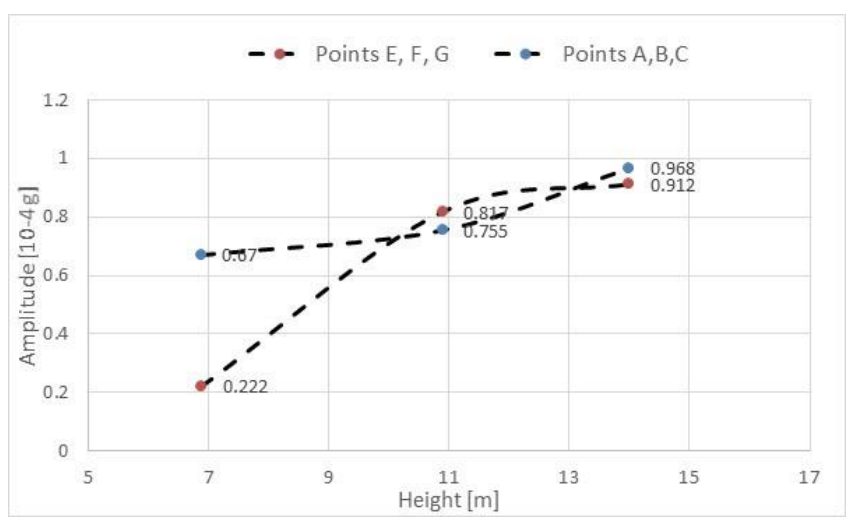

Figure 23. Excitation Frequency of $18 \mathrm{~Hz}$ : peak amplitude of the analyzed points, $x$ direction 


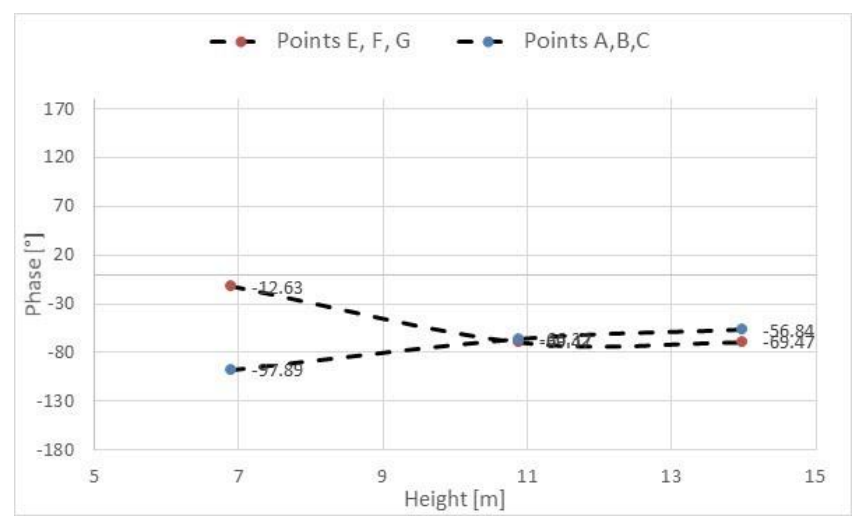

Figure 24. Excitation Frequency of $18 \mathrm{~Hz}$ : phase shift of the analyzed points, $x$ direction

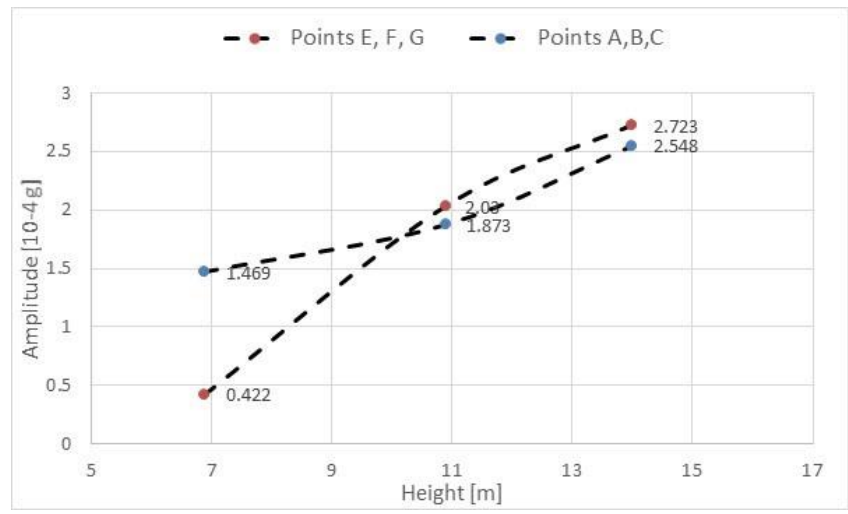

Figure 25. Excitation Frequency of $20 \mathrm{~Hz}$ : peak amplitude of the analyzed points, $x$ direction.

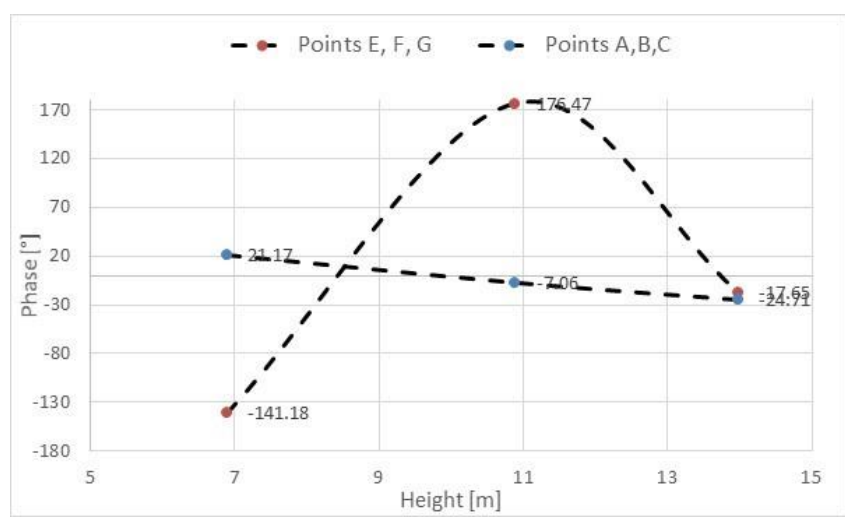

Figure 26. Excitation Frequency of $20 \mathrm{~Hz}$ : phase shift of the analyzed points, $x$ direction

It is important to remark that all the considerations carried out in this paragraph permit to characterize the modes of the instrumented tower by only analysing very short forced tests with respect to the long acquisitions in environmental conditions which often, for structure not streamline, do not permit any dynamic analysis. Moreover, the proposed procedure permits to individuate with accuracy the transmitted vibrational effect on the different monitored points of the structure. This information can also be used for validating models of the structure with information related to the damping ratio effect between the monitored points of the structure at the different forcing frequencies.

\section{CONCLUSIONS}

The paper discusses the dynamic experimental tests performed on the clock tower of the Swabian Castle of Trani and the subsequent dynamic identification. The tests have been conducted acquiring the vibrations induced by environmental actions and also by installing an electro-hydraulic shaker device at the base of the tower. The analysis of the environmental vibrations performed in the framework of the OMA has allowed the identification of the natural frequencies.

The main novelty here proposed is related to an innovative strategy for analyzing the forced vibrations with quick tests during which the structure was excited by a vibrodyne placed on its ground. The short tests were carried out by driving the vibrodyne with different frequencies and the strategy here proposed permits to insulate, by means of opportune digital band-pass filters, the sinusoidal component at the excitation frequencies in all the monitored points. The sinusoidal component may be used for determining, at the different frequencies, the transmitted amplitude and the phase shift between the different points of the structure. This information may confirm, as demonstrated in this case, the modal shapes of the structure, and also allows to tune opportune models by ensuring the relevant characteristics of structural transmission damping ratio.

\section{ACKNOWLEDGEMENT}

The authors gratefully acknowledge the funding by Structural Monitoring of ARTistic and historical BUILding Testimonies - (S.M.ART. BUIL.T.) Project of the European Territorial Cooperation Programme Greece-Italy 2007-2013 and by PRIN-MIUR 2010 research project entitled "Dynamics, Stability and Control of Flexible Structures".F. Paparella and the staff of the "Laboratorio M. Salvati" of the Polytechnic of Bari are gratefully acknowledged for their help during the tests

\section{REFERENCES}

[1] C. Gentile, A. Saisi, Ambient vibration testing of historic masonry towers for structural identification and damage assessment, Constr. Build. Mater., 2007, 21, 6, pp. ${ }^{\circ} 1311-1321$.

[2] C. Gentile, A. Saisi, A. Cabboi, Structural Identification of a Masonry Tower Based on Operational Modal Analysis, Int. J. Archit. Herit., 2014, 9, 2, pp. 98-110.

[3] S. Ivorra, F. J. Pallarés, Dynamic investigations on a masonry bell tower, Eng. Struct., 2006, 28, 5 pp 660-667.

[4] D. Foti, M. Diaferio, N. I. Giannoccaro, S. Ivorra, Structural identification and numerical models for slender historical structures. Handbook of Research on Seismic Assessment and Rehabilitation of Historic Structures, 2015, pp. 674-703.

[5] D. Bru, S. Ivorra, F. J. Baeza, R. Reynau, D. Foti, OMA dynamic identification of a masonry chimney with severe cracking condition, in $6^{\text {th }}$ International Operational Modal Analysis Conference, IOMAC 2015.

[6] L. F. Ramos, L. Marques, P.B. Lourenco, G. De Roeck, A. Campos-Costa, J. Roque, Monitoring historical masonry structures with operational modal analysis: Two case studies, Mechanical Systems and Signal Processing, 2010, 24, pp. 1291 1305.

[7] M. Diaferio, N. I. Giannoccaro, D. Foti, S. Ivorra, Identification of the modal properties of an historic masonry clock tower, in SAHC2014 -2014, 9th International Conference on Structural Analysis of Historical Constructions.

[8] A. Tomaszewska, C. Szymczak, Identification of the Vistula Mounting tower model using measured modal data, Engineering Structures, 2012, 42, pp. 342-348. 
[9] M. Diaferio, D. Foti, C. Gentile, N.I. Giannoccaro, A. Saisi, Dynamic testing of a historical slender building using accelerometers and radar, Prooceedings of $6^{\text {th }}$ International Operational Modal Analysis Conference, IOMAC 2015; Abba Hotel Gijon; Spain; 12-14 May 2015.

[10] J. Snoj, M. Österreicher, M. Dolšek, The importance of ambient and forced vibration measurements for the results of seismic performance assessment of buildings obtained by using a simplified non-linear procedure: Case study of an old masonry building, Bull. Earthq. Eng., 2013, 11, 6, pp. 2105-2132.

[11] G. Bartoli, M. Betti, and S. Giordano, In situ static and dynamic investigations on the 'Torre Grossa' masonry tower, Eng. Struct., 2013, 52, pp. 718-733.

[12] A. De Sortis, E. Antonacci, F. Vestroni, Dynamic identification of a masonry building using forced vibration tests, Eng. Struct., 2005, 27, 2, pp. 155-165.

[13] M. Diaferio, D. Foti, N. I. Giannoccaro, S. Ivorra, Optimal model through identified frequencies of a masonry building structures with wooden floors" Int. J. of Mech., 2014, 8, pp. 282 288.

[14] E. Yu, D. H. Whang, J. P. Conte, J. P. Stewart, J. W. Wallace, Forced vibration testing of buildings using the linear shaker seismic simulation (LSSS) testing method. Earthq, Eng. Struct. Dyn. 2005; 34, pp. 737-761.

[15] E. M., Tronci, D. Pietrosanti, G. Cordisco, M. De Angelis, Vibration analysis of the civic tower in Rieti, Procedia Engineering, 2017, 199 pp. 2268-2273.

[16] F. Fabbrocino, I. Farina, M. Modano, Loading noise effects on the system identification of composite structures by dynamic tests with vibrodyne, 2017, Composites Part B 115 pp. 376-383.

[17] A. Barbieri, A Borri, M. Corradi, A. Di Tommaso, Dynamic behaviour of masonry vaults repaired with FRP: experimental analysis, In: Proc. of the $6^{\text {th }}$ international conference of the British Masonry society, UK; 2002. pp. 7-16.

[18] F. Bastianini, M. Corradi, A. Borri, A. Di Tommaso, Retrofit and monitoring of an historical building using "Smart" CFRP with embedded fibre optic Brillouin sensors, Constr Build Mater 2005, 19(7), pp. 525-535.

[19] F. Prete. I centri storici tra cultura, arte e tecniche. Il caso studio di Trani/Historical centres among culture, art and tecniques. The case study of Trani, Bari: Adriatica Editrice, 2014 (in Italian).

[20] Artemis Modal Pro v4.5. Structural Vibrations Solutions. Aalborg, Denmark. 2016.

[21] Digital Signal Processing Committee of the IEEE Acoustics Speech and Signal Processing Society., Programs for Digital Signal Processing. Algorithm 5.2, New York: IEEE Press, 1979.

[22] The Mathworks, MATLAB, Natick, MA, 2015.

[23] L. Spedicato, I. Armeni, N. I. Giannoccaro, M. Avlonitis, S. Papavlasopoulos, A dynamic identification of a historical building using accelerometers with interface modules and a digital synchronization method, Key Eng. Mater., 2014, 628, pp. 204 211.

[24] N. I. Giannoccaro, L. Spedicato, D. Foti, A digital analysis of the experimental accelerometers data used for buildings dynamical identification, in EESMS 2016 - 2016 IEEE Workshop on Environmental, Energy, and Structural Monitoring Systems, Proceedings, 2016.

[25] M. Diaferio, D. Foti, N. I. Giannoccaro, S. Ivorra, Experimental methodology for measuring the structural dynamic transmission damping of a cultural heritage tower, Proc. of Imeko, International Conference on Metrology for Archeology and Cultural Heritage, Lecce, 23-25 October 2017, pp. 1-6, 2017. 